\title{
Hubungan antara Parental Bonding dengan Kecenderungan Perilaku Seksual Pranikah pada Remaja Akhir yang Berpacaran
}

\author{
SYARIFAH AYU DWI ARIESA PUTRI \& PRIHASTUTI* \\ Departemen Psikologi Pendidikan dan Perkembangan, Fakultas Psikologi Universitas Airlangga
}

\begin{abstract}
ABSTRAK
Penelitian ini bertujuan untuk melihat apakah terdapat hubungan antara parental bonding dengan kecenderungan perilaku seksual pranikah pada remaja akhir berpacaran. Parental bonding merupakan keterikatan secara fisik dan emosional antara orangtua dan anak, dan menjadi dasar pembentukan emosi anak. Kecenderungan perilaku seksual pranikah yaitu intensi individu atas kemungkinan dirinya untuk melakukan perilaku tersebut. Subjek dalam penelitian ini adalah remaja akhir (18-21 tahun) yang berpacaran. Jumlah responden sebanyak 248 orang. Alat ukur yang digunakan adalah Parental Bonding Instrument, dan skala kecenderungan perilaku seksual pranikah. Analisis data menggunakan uji korelasi teknik Sperman's rho dan menunjukkan nilai koefisian korelasi sebesar -0,295 $(p<0.05)$, sehingga terdapat hubungan signifikan antara parental bonding dengan kecenderungan perilaku seksual pranikah dengan arah hubungan negatif.
\end{abstract}

Kata kunci: kecenderungan perilaku seks, parental bonding, remaja

\begin{abstract}
This study aims to see whether there is a relationship between parental bonding with the tendency of premarital sexual behavior in late adolescents dating. Parental bonding is a physical and emotional attachment between parents and children, and is the basis for children's emotional formation. The tendency of premarital sexual behavior is the intention of the individual over the possibility of himself to do the behavior. The subjects in this study were late teens (18-21 years) who were dating. The number of respondents was 248 people. The measuring instrument used was the Parental Bonding Instrument, and the scale of the predisposition to premarital sexual behavior. Data analysis used Sperman's rho technique correlation test and showed a correlation coefficient of -0.295 ( $p<0.05$ ), so there was a significant relationship between parental bonding with the tendency of premarital sexual behavior with the direction of a negative relationship.
\end{abstract}

Key words: adolescents, parental bonding, sexual behavior tendencies

INSAN Jurnal Psikologi dan Kesehatan Mental, 2019, Vol. 4(2), 76-82, doi: 10.20473/jpkm.v4i22019.76-82

Dikirimkan: 16 Oktober 2019 Diterima: 10 Desember 2019 Diterbitkan: 27 Februari 2020

Editor: Rizqy Amelia Zein

*Alamat korespondensi: Fakultas Psikologi Universitas Airlangga, Jalan Airlangga 4-6 Surabaya 60286. Pos-el: prihastuti@psikologi.unair.ac.id

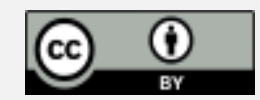

Naskah ini merupakan naskah dengan akses terbuka dibawah ketentuan the Creative Common Attribution License (http://creativecommons.org/licenses/by/4.0), sehingga penggunaan, distribusi, reproduksi dalam media apapun atas artikel ini tidak dibatasi, selama sumber aslinya disitir dengan baik. 


\section{P E N D A H U L U A N}

Remaja merupakan suatu periode transisi dalam rentang kehidupan seorang manusia yang menjembatani antara masa anak-anak dengan masa dewasa (Santrock, 2011). Perubahan perkembangan dalam masa remaja sedari awal hingga akhir tentu berbeda, oleh karena itu, Monks, Knoers, \& Haditono (2014) membagi masa remaja menjadi tiga fase yaitu fase remaja awal (rentang usia 12-15 tahun), fase remaja madya (rentang usia 15-18 tahun), dan fase remaja akhir (rentang usia 18-21 tahun) (Monks, dkk., 2014).

Pada masa remaja terjadi berbagai perubahan pada beberapa aspek perkembangannya karena masa remaja merupakan masa transisi. Perubahan tersebut terjadi pada aspek kognitif, fisik, dan sosioemosinya. Menurut Piaget dalam Santrock (2011), menyatakan bahwa tahap perkembangan kognitif remaja berada pada tahap operasional formal. Selain perkembangan dalam aspek kognitif, remaja juga mengalami perkembangan pada aspek fisik mulai dari kematangan seksual, kematangan fisik, perubahan hormonal, dan mulai terjadinya masa pubertas. Pada masa ini remaja akan mulai merasakan adanya hasrat seksual yang diakibatkan oleh perubahan hormon (Santrock, 2011). Menurut Erikson (1968) dalam teori psikososialnya, remaja ada pada fase identity vs identity confussion. Pada masa remaja ini juga seseorang mulai tertarik pada lawan jenisnya dan mulai menjalin hubungan romantis (Monks, dkk, 2014). Kemudian Menurut Hurlock (1999), salah satu perkembangan remaja yang lain yaitu pada perkembangan emosi. G. Stanley Hall (1904 dalam Santrock, 2011) menjelaskan mengenai "storm and stress" yang terjadi pada masa remaja sebagai masa yang banyak diwarnai oleh konflik dan perubahan mood. Peluang untuk tumbuh dalam aspek fisik, kognitif, dan psikososial pada remaja memungkinkan mereka mengalami perubahan yang menyimpang seperti mengonsumsi minuman keras, penyalahgunaan obat-obat terlarang, dan aktivitas seksual (Papalia, 2008 dalam Regina, 2015)

Kemungkinan adanya perubahan yang menyimpang pada remaja dapat juga dikatakan sebagai kecenderungan seorang remaja untuk berperilaku menyimpang pada aktivitas seksualnya seperti kecenderungan untuk melakukan perilaku seksual pranikah. Kecenderungan sendiri menurut Fishbein dan Ajzen (2011) diartikan sebagai indikasi kesiapan seseorang untuk melakukan suatu perilaku, kesiapan untuk bertindak, diwakili oleh niat kecenderungan dipengaruhi oleh beberapa hal yaitu (1) behavioral beliefs, kemudian dapat berkembang menjadi attitudes toward the behavior; (2) normative beliefs, kemudian akan menghasilkan perceived; (3) control beliefs kemudian akan menghasilkan perceived behavioral control. Attitudes, perceived norms, dan perceived behavioral control mengarah pada intensi terjadinya perilaku, atau kesiapan untuk melakukan perilaku (Fishbein \& Ajzen, 2011). Adapun Crockett, Raffaelli, \& Moilanen (2008) mendefinisikan perilaku seksual remaja adalah segala bentuk perilaku yang terlibat dalam spektrum perilaku seksual mulai dari fantasi, stimulasi diri (masturbasi), bermesraan (making out) hingga berbagai bentuk hubungan seksual.

Pada survei Litbang Kesehatan yang bekerja sama dengan UNESCO pada tahun 2017, secara umum 80\% wanita dan $84 \%$ pria pernah berpacaran. Kelompok usia pertama kali berpacaran paling banyak pada usia 15-17 tahun, dimana 45\% wanita dan 44\% pada pria. Survei tersebut juga menunjukan sebanyak $56 \%$ remaja Indonesia pernah melakukan seks pranikah. Disebutkan pula pada survei tersebut, bahwa usia kali pertama melakukan perilaku seksual pranikah pada pria sebanyak $74 \%$ yaitu pada rentang usia 15-19 tahun dan 12\% pada rentang usia 20-24 tahun, sedangkan pada perempuan sebanyak 59\% terjadi pada rentang usia 15-19 tahun dan 22\% pada usia 20-24 tahun (Dinkes, 2017). Berdasarkan data RISKESDAS (Riset Kesehatan Dasar) pada tahun 2010 mengenai usia pertama kali melakukan hubungan seksual remaja laki-laki dan perempuan didapatkan hasil, pada usia $\leq 14$ tahun sebanyak 246 remaja, usia 15-17 tahun sebanyak 2098 remaja, usia 18-21 tahun sebanyak 4936 remaja, dan 22-24 tahun sebanyak 1401 remaja (Pratiwi \& Basuki, 2010). 
Penelitian yang dilakukan oleh Crockett, Raffaelli, \& Moilanen, (2008) menyebutkan beberapa faktor yang memengaruhi perilaku seks pranikah, yaitu (1) Faktor biologis, seperti pubertas, faktor genetik, dan model biososial, (2) faktor sosiokultural, seperti faktor keluarga, faktor teman sebaya, pasangan romantis, faktor lingkungan (neighborhood), dan media, (3) faktor psikologis dan perilaku, seperti sikap dan nilai-nilai, pencapaian akademik dan pendidikan dan penyesuaian psikososial. Crockett, Raffaelli, \& Moilanen, (2008) menjelaskan kembali lebih dalam mengenai faktor keluarga yaitu hubungan orangtua dengan anak, keterlibatan kontrol orangtua, dan juga komunikasi antara orangtua dengan anak semuanya memengaruhi perilaku seksual pranikah remaja. Kualitas hubungan yang baik ini secara tidak langsung dapat mencegah anak agar tidak terpengaruh teman sebaya dalam perilaku seks yang menyimpang (Crockett, Rafaelli, \& Moilanen, 2008). Melalui faktor-faktor yang telah disebutkan, keluarga sebagai sistem sosial dimana individu pertama kali mengenali dunia sosialnya, khususnya orang tua memainkan peran penting dalam kecenderungan perilaku seksual pranikah pada remaja.

Di Indonesia, remaja, terutama mereka yang belum menikah, tidak menerima informasi yang cukup mengenai masalah kesehatan reproduksi. Informasi mengenai pubertas dan kesehatan seksual, sebagian besar diperoleh dari teman, media massa, dan guru agama. Namun informasi yang didapatkan kemungkinan tidak lengkap, tidak informatif atau malah cenderung dialihkan oleh pesan agama dan moral. Kebanyakan orang tua di Indonesia masih memegang norma-norma konservatif, mereka merasa tidak nyaman mendiskusikan masalah seksual dengan anak remaja mereka. Pendidikan seks juga jarang ditemukan di kurikulum sekolah di Indonesia. Berbicara tentang seks di depan umum juga masih dianggap sebagai hal yang tabu, dan ditambah adanya keyakinan kuat bahwa seks harus diperlakukan sebagai masalah pribadi dan bukan urusan publik (Situmorang, 2003).

Piaget menyatakan bahwa hubungan antara orangtua dengan remaja berbeda dengan hubungan remaja dengan teman sebaya (Santrock, 2002). Hubungan orangtua dan remaja merupakan hubungan yang timbal balik, dengan adanya rasa percaya, saling mengerti, dan juga saling menerima satu sama lain (Gunarsa, 2008). Salah satu konsep yang menggambarkan hubungan antara orangtua dengan anak yaitu adanya bonding atau ikatan yang biasa disebut dengan parental bonding.

Berdasarkan kondisi di Indonesia yang menganggap topik seksual merupakan hal yang tabu dan juga berdasarkan penelitian-penelitian terdahulu yang menyatakan bahwa keluarga khususnya orangtua memberikan peran penting terhadap kecenderungan perilaku seksual pranikah seorang remaja. Dapat disimpulkan bahwa saat remaja tidak mendapatkan informasi yang cukup mengenai seks di lingkungan

keluarga dapat memberikan dampak pada perilaku seksual remaja itu sendiri. Oleh karena itu peneliti ingin melihat apakah parental bonding antara orangtua dan remaja memiliki hubungan dengan kecenderungan perilaku seksual pranikah pada remaja.

\section{E T O D E}

\section{Partisipan}

Penelitian ini melibatkan 248 remaja. Partisipan penelitian didominasi oleh kelompok usia 21 tahun. Adapun jumlah remaja berusia 18 tahun yang menjadi subjek dalam penelitian ini ialah sebanyak 12 orang (4,8\%), 19 tahun 32 orang (12,9\%), 20 tahun 39 orang (15,7\%), dan 21 tahun sebanyak 165 orang (66,5\%). Sedangkan berdasarkan jenis kelamin, subjek didominasi oleh perempuan, yaitu mencapai 206 $(83,1 \%)$ sedangkan laki-laki $42(16,9 \%)$. 


\section{Prosedur}

Tipe penelitian ini yaitu kuantitatif (explanatory research) menggunakan metode survei. Subjek dalam penelitian ini yaitu remaja akhir (18-21 tahun) yang berpacaran sebanyak 248 subjek. Teknik analisis data yang digunakan menggunakan uji korelasi dengan Spearman's rho Correlation Test. Melalui metode ini peneliti akan mendapatkan arah hubungan antara parental bonding dengan kecenderungan perilaku seksual pranikah.

Variabel bebas pada penelitian ini yaitu parental bonding. Luanpreda dan Verma (2015) mengartikan parental bonding sebagai keterikatan secara fisik dan emosional yang terjadi antara orangtua dan anak, terutama ibu, yang berlangsung sejak lahir dan menjadi dasar pembentukan emosi anak. Variabel bebas ini terdiri dari dua dimensi yaitu care dan control (Parker, Tupling, \& Brown, 1979). Variabel terikat dalam penelitian ini yaitu kecenderungan perilaku seks pranikah. Kecenderungan perilaku seks pranikah adalah intensi seseorang untuk melakukan segala bentuk perilaku yang terlibat dalam spektrum perilaku seksual mulai dari fantasi, stimulasi diri (masturbasi), bermesraan (making out) hingga berbagai bentuk hubungan seksual (Crockett, Rafaelli, \& Moilanen, 2008).

\section{Pengukuran}

Instrumen yang digunakan adalah Parental Bonding Instrumen yang dibuat oleh Parker, Tupling, \& Brown (1979) dan telah ditranslasi oleh Tustikarana (2016), terdiri dari 14 aitem yang disusun berdasarkan dua dimensi yaitu care dan control dengan nilai reliabilitas 0,921. Sedangkan skala kecenderungan perilaku seks pranikah adalah alat ukur yang dibuat oleh Devina (2018), terdiri dari 10 aitem dengan nilai reliabilitas 0,831 .

\section{Analisis data}

Sebelum melakukan uji hipotesis, penulis terlebih dahulu melakukan uji asumsi diantaranya uji normalitas dan uji linearitas. Hasil uji normalitas menunjukkan bahwa taraf signifikansi variabel parental bonding menunjukkan nilai 0,003 maka dapat dikatakan distribusi data pada variabel parental bonding tidak normal. Sedangkan pada variabel kecenderungan perilaku seksual pranikah, nilai yang didapatkan ialah 0,097. Hal ini menunjukkan bahwa distribusi data pada variabel kecenderungan perilaku seksual pranikah adalah normal. Sedangkan hasil untuk uji linearitas didapatkan nilai signifikansi linearity 0,000 yang berarti kedua variabel linear. Berdasarkan hasil uji asumsi, teknik statistik yang digunakan adalah statistik non-parametrik, yaitu Spearman's rho.

\section{H A S IL PENELITIAN}

Didapatkan nilai koefisien korelasi yang cenderung lemah dan negative $(\rho=-0,295, p<0.05)$. Hal tersebut menunjukkan bahwa terdapat hubungan negatif yang signifikan antara parental bonding dengan kecenderungan perilaku seksual pranikah pada remaja akhir berpacaran. Hubungan negatif yang ditemukan dalam penelitian ini menjelaskan bahwa semakin tinggi kualitas parental bonding, maka kecenderungan perilaku seksual pranikah akan semakin rendah, dan begitu pula sebaliknya.

\section{I S K US I}

Adapun hasil penelitian ini sejalan dengan pernyataan bahwa keluarga merupakan sumber utama bagi perkembangan dan pertumbuhan seorang anak. Bronfenbrenner (1979) menyebutkan bahwa keluarga

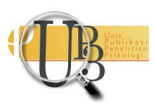


merupakan lingkungan yang paling pertama dan utama dalam proses perkembangan seorang anak. Termasuk dalam perkembangan seksual seorang individu, peran kelurga tentu sangat besar. Saat remaja sedang berada pada fase pencarian identitas diri, keluarga merupakan sumber utama untuk pencarian informasi. Berdasarkan budaya di Indonesia bahwa remaja akhir masih berada pada tanggung jawab orangtua, mengingat subjek pada penelitian ini merupakan remaja akhir yang berusia 18-21 tahun dan belum menikah. Melihat berdasarkan budaya Indonesia yang permisif, dimana pembicaraan mengenai seksual masih tabu. Oleh karena itu orangtua memegang peranan yang cukup penting dalam pemberian informasi kepada remaja agar tidak terjerumus dalam informasi yang salah.

Hasil penelitian ini juga didukung oleh penelitian sebelumnya yang dilakukan oleh Cahyani (2017) mengenai hubungan parental bonding dan self-esteem dengan perilaku seksual remaja, memberikan hasil bahwa parental bonding memiliki hubungan dengan perilaku seksual remaja. Dimana ketika pemberian remaja memiliki tipe ikatan optimal dimana care berada pada tingkatan tinggi, yaitu orangtua dan remaja saling terbuka satu sama lain kemudian juga pemberian control rendah, yaitu orangtua tidak terlalu mengekang anak dan tetap memberikan batasan sewajarnya maka perilaku seksual pada remaja tergolong rendah.

Pernyataan lain yang mendukung hasil penelitian ini yaitu bahwa hubungan ikatan (bonding) orangtuaremaja yang berkualitas lebih tinggi dikaitkan dengan tingkat yang lebih rendah dari hubungan seksual yang beresiko dan juga permulaan remaja untuk melakukan hubungan seksual. Sehingga keterikatan atau bonding orang tua dan keluarga memberikan pengaruh positif pada perilaku seksual remaja (Markham et al., 2010 dalam Daire, dkk, 2013) Terdapat juga penelitian yang menyatakan bahwa perilaku seksual yang dimulai lebih awal berhubungan dengan tingkat pengawasan orang tua yang rendah (Zimmer-Gembeck, dkk, 2008 dalam Santrock, 2011).

Di samping penemuan mengenai hubungan signifikan antara parental bonding dengan kecenderungan perilaku seksual pranikah, kategorisasi skor subjek yang didapatkan dalam penelitian ini menunjukkan bahwa mayoraitas remaja akhir yang menjadi subjek berada pada tingkatan sedang dalam hubungannya dengan parental bonding, yaitu sebanyak 34,3\%, sedangkan kategori lain, yaitu sangat tinggi hanya 4,4\%, tinggi 32,3\%, rendah 20,2\%, dan sangat rendah 8,9\%. Dari pemaparan tersebut, dapat terlihat bahwa terdapat $29 \%$ responden yang hubungan parental bonding-nya dalam kategori rendah dan sangat rendah, hal ini tentunya tidak dapat kita abaikan, karena meskipun persentase ini tidak terlalu besar, namun rendahnya hubungan parental bonding di masa remaja tetap dapat menjadi potensi akan sebuah permasalahan seperti perilaku seksual pranikah. Berbagai permasalahan ini tentunya tidak kita inginkan untuk terjadi, maka dari itu rendahnya hubungan ikatan antara anak dan remaja atau parental bonding yang ditemukan dalam penelitian ini perlu mendapatkan perhatian.

Berdasarkan uraian diatas dapat disimpulkan bahwa hasil penelitian ini telah mampu menjawab rumusan masalah dalam penelitian, yaitu terdapat hubungan negatif yang signifikan antara parental bonding dengan kecenderungan perilaku seksual pranikah remaja, dimana semakin tinggi ikatan parental bonding maka kecenderungan perilaku seksual pranikah pada remaja akan semakin rendah. Penemuan ini diharapkan dapat menjadi tambahan pengetahuan terutama bagi para orangtua, bahwa antara care (kepedulian) dan juga control (pengawasan) yang diberikan kepada anak, akan menghasilkan ikatan atau bonding yang lebih baik jika keduanya seimbang.

\section{S I M P U L A N}

Berdasarkan hasil analisis data dapat ditarik kesimpulan bahwa terdapat hubungan antara parental bonding dengan kecenderungan perilaku seksual pranikah pada remaja akhir berpacaran. Adapun koefisien korelasi yang didapatkan menunjukkan arah hubungan yang negatif, dimana hal ini 
mengindikasikan semakin baik ikatan antara orangtua dan anak, maka akan semakin rendah kecenderungan perilaku seksual pranikah pada remaja dan begitu juga sebaliknya.

Saran bagi peneliti selanjutnya sebaiknya dilakukan kontrol pada apakah subjek tinggal bersama dengan orangtua atau tidak dan diharapkan lebih teliti dalam pemilihan subjek penelitian agar dapat lebih menguatkan hasil penelitian dan lebih tepat sasaran terhadap permasalahan yang ada di lapangan.

Saran bagi orangtua untuk dapat menciptakan situasi atau iklim yang nyaman bagi anak, sehingga anak dapat menjadi lebih terbuka dan menganggap keluarga sebagai sumber utama untuk mencari informasi. Sedangkan untuk remaja, diharapkan memiliki kesadaran yang lebih untuk berusaha dalam mengevaluasi lingkungan pergaulan mereka.

\section{U C A P A N T ERIMA KASIH}

Penulis mengucapkan terima kasih pada seluruh responden yang terlibat dalam penelitian ini sehingga penelitian ini dapat terselesaikan dengan baik.

\section{DEKLARASI POTENSI TERJADINYA KONFLIK KEPENTINGAN}

Syarifah Ayu Dwi Ariesta Putri dan Prihastuti tidak bekerja, menjadi konsultan, memiliki saham, atau menerima dana dari perusahaan atau organisasi mana pun yang akan mengambil untung dari naskah ini, dan telah mengungkapkan bahwa ia tidak memiliki afiliasi selain yang telah disebut di atas.

\section{PUSTAKA ACUAN}

Bronfenbrenner, U. (1979). Bronfenbrenner, U. (1979). The ecology of human development. London: Harvard University Press.

Crockett, L. J., Raffaelli, M., \& Moilanen, K. L. (2008). Adolescent Sexuality: Behavior and Meaning. Blackwell Handbook of Adolescence, 371-392. https://doi.org/10.1002/9780470756607.ch18

Daire, A. P., Turk, J., Johnson, J. M., \& Dominguez, V. (2013). Parental bonding and its effect on adolescent substance use and sexual debut. Adultspan Journal, 12(1), 54-64. https://doi.org/10.1002/j.21610029.2013.00015.x

Devina, A., Psikologi, F., \& Airlangga, U. (2018). Hubungan antara kualitas hubungan anak dan ayah dengan kecenderungan perilaku seksual pranikah pada remaja.

Dinkes, R. (2017). Survei Demografi Dan Kesehatan. Badan Kependudukan Dan Keluarga Berencana Nasional, 1-606. Retrieved from http://www.dhsprogram.com.

Erikson, E. (1968). Youth: Identity and Crisis. In New York, NY: WW.

Fishbein, M., \& Ajzen, I. (2011). Predicting C hanging B ehavior.

Gunarsa, S. D. (2008). Psikologi perkembangan anak dan remaja. BPK Gunung Mulia.

Markham, C. M., Lormand, D., Gloppen, K. M., Peskin, M. F., Flores, B., Low, B., \& House, L. D. (2010). Connectedness as a Predictor of Sexual and Reproductive Health Outcomes for Youth. Journal of Adolescent Health. https://doi.org/10.1016/j.jadohealth.2009.11.214

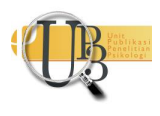


Monks, F. J., Knoers, A. P., \& Haditono, S. R. (2014). Psikologi Perkembangan: Pengantar dalam berbagai bagiannya. Yogyakarta: Gadjah Mada University Press.

Pak Luanpreda, P. verma. (2015). The influence of parental bonding on depresion, shame, and anger among thai middle school children, being mediated by peer victimzation (victim of bullying): Apath analytical study. Scholar, 7(2), 137-149. Retrieved from http://www.assumptionjournal.au.edu/index.php/Scholar/article/view/1512/1305

Parker, G., Tupling, H., \& Brown, L. B. (1979). A Parental Bonding Instrument. British Journal of Medical Psychology, 52(1), 1-10. https://doi.org/10.1111/j.2044-8341.1979.tb02487.x

Pratiwi, N. L., \& Basuki, H. (2010). Analisis Hubungan Perilaku Seks Pertamakali Tidak Aman pada Remaja Usia 15-24 tahun dan Kesehatan Reproduksi. Buletin Penelitian Sistem Kesehatan.

REGINA, C. (2015). Hubungan Attachment Orang Tua Dengan Kenakalan Remaja Mts Pgai Padang. Fakultas Keperawatan. Retrieved from http://repo.unand.ac.id/184/

Santrock, J. (2002). Life-span Development Perkembangan Hidup Jilid 1 Edisi Kelima. Jakarta: Erlangga.

Santrock, J. W. (2011). Life-Span Development (13th ed.). In McGraw-Hill.

Situmorang, A. (2003). Adolescent Reproductive Health in Indonesia. In STARH Program.

Tustikarana, A. M. (2016). Hubungan Antara Parental Bonding Dengan Regulasi Emosi Pada Remaja. 